Research Article

\title{
Characteristics of the Interface between Bamboo Grids and Reinforced Soil of High-Filled Embankments in Loess Areas
}

\author{
Jingwei Zhang, ${ }^{1}$ Jia Li $\mathbb{D}^{2},{ }^{2}$ Julong Wang, ${ }^{2}$ and Shuaiqi $\mathrm{Xu}^{2}$ \\ ${ }^{1}$ School of Civil Engineering, Zhengzhou University, Zhengzhou 450002, China \\ ${ }^{2}$ School of Hydraulic Science and Engineering, Zhengzhou University, Zhengzhou 450002, China \\ Correspondence should be addressed to Jia Li; lijia@zzu.edu.cn
}

Received 6 April 2021; Accepted 8 July 2021; Published 19 July 2021

Academic Editor: Jian Ji

Copyright ( 2021 Jingwei Zhang et al. This is an open access article distributed under the Creative Commons Attribution License, which permits unrestricted use, distribution, and reproduction in any medium, provided the original work is properly cited.

There are a large number of high-filled and deep-dug highways in loess areas. The differential settlement between the filled and undisturbed soils is the main cause of damage. Bamboo grids are good reinforcement and flexural tensile materials for highway subgrades, and the properties of the interface between the bamboo grid and loess soil affect the safety and stability of embankments. First, the feasibility of bamboo grid application in high-filled embankments in loess areas was verified based on a durability analysis and test of the mechanical properties of bamboo. Then, a series of large-scale direct shear tests were carried out to determine the shear properties of the interface between bamboo grids and loess soils. The influential factors of vertical stress, shear rate, grid spacing, and compactness on the shear properties were studied, and the related mechanism was discussed. The results show that bamboo grids enhance the shear strength of loess soils more than geogrids under different vertical stresses because of the passive friction resistance between the vertical and horizontal ribs and soil particles, the bite force of particle skeletons, and the surface friction of grids. Bamboo grids enhance the stability and shear resistance of soils because of their good deformation performance, and thus, the shear rate effect within $7 \mathrm{~mm} / \mathrm{min}$ can be negligible. The greater the relative compaction of the subgrade soil, the better the reinforcement effect owing to the greater cohesive force, greater internal friction angle, and better bite force. The variation in grid spacing changes the embedded effect of soil, side friction resistance, and size of the contact area. The shear resistance has an optimal value, which first increases and then decreases. Therefore, in practical applications, it is necessary to test the optimal bamboo grid spacing for a project.

\section{Introduction}

China has the most widely distributed and largest loess plateau in the world, comprising various landforms such as loess tablelands, beams, ridges, hills, and gullies (see Figure 1). Therefore, many high-filling and deep-excavation subgrades are necessary for highway construction in the loess distribution areas (Figure 2). The uneven settlement of the filled subgrade soils and undisturbed subgrade soil is the main cause of highway damage. The conventional method uses geosynthetics such as geogrids and geocells to restrain the local and uneven settlement of embankments [1-3]. However, the cost of geosynthetics is high [4], and they do not have bending capacity. Thus, it is difficult to place them at the interface of high and steep slopes of embankments to prevent soil sliding [5].
Bamboo has always been a good tensile reinforcement material [6, 7], which not only has good mechanical properties but also can be made in local regions and meet the requirements of "low carbon." [8] Among them, Phyllostachys pubescens and Neosinocalamus affinis are commonly used in engineering. Phyllostachys pubescens is the most widely cultivated bamboo species in China, with the trunk height of more than $20 \mathrm{~m}$ and the thickness of more than $20 \mathrm{~cm}$ (Figure 3). Neosinocalamus affinis is distributed in Southwest China, with the trunk height of 5-10 $\mathrm{m}$ and thickness of 3-6 cm (Figure 4). Early studies [9] have shown that a reinforcement with bending capacity can increase the subgrade bearing capacity by $15 \%-46 \%$ and significantly reduce the soil sliding along the slope. In terms of mechanical properties, Ismail et al. [10] studied the tensile 


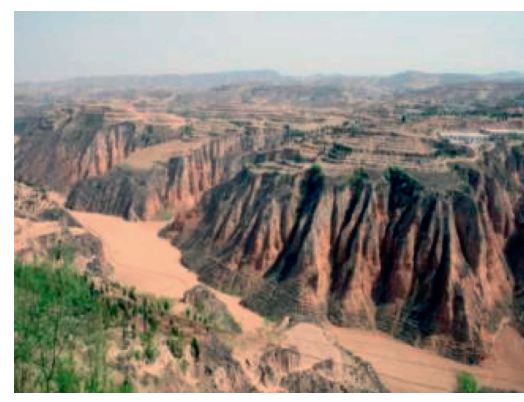

Figure 1: Loess landform.

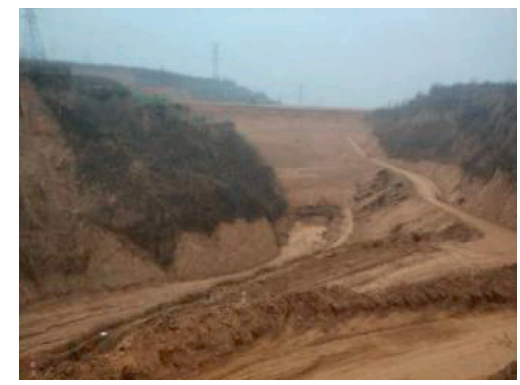

FIgURE 2: Loess high-fill embankment.

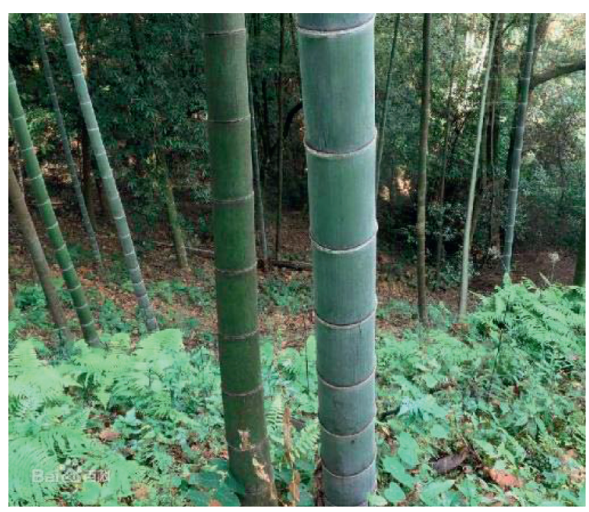

Figure 3: Phyllostachys pubescens.

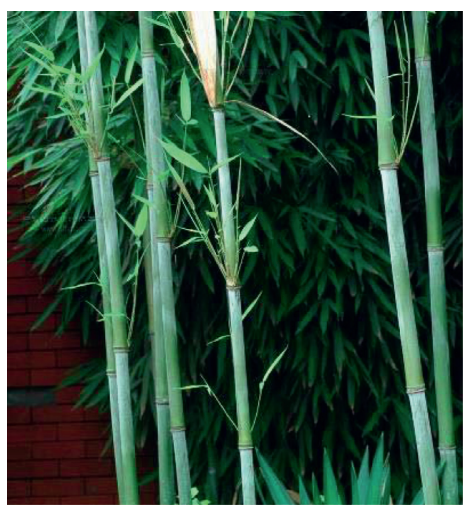

Figure 4: Neosinocalamus affinis.

strength, tensile film content, tear strength, elongation at break, and hardness of bamboo bar composites. The results showed that the properties of raw materials were strengthened by adding bamboo bars. Shao [11] conducted a large deformation test under static pressure to study the mechanical behavior of bamboo under different temperature and constraint conditions and established the stress-strain relationship under large compression deformation. Zhou et al. [12] obtained the relationship between the macromechanical properties of bamboo and the microvolume ratio of the vascular bundle by a macrotest and microanalysis. Li et al. [13] discussed the failure mechanism of bamboo and proposed a calculation formula for the ultimate bearing capacity considering the eccentric distance effect through eccentric compression tests. In terms of the interaction between bamboo grids and soil, Wei et al. [14] obtained the shear characteristics and analyzed the reinforcement mechanism of bamboo grid-reinforced soil through triaxial tests of remolded, plain, and reinforced soils. Wang et al. [15] studied the interface characteristics of bamboo-reinforced stone-slag-filled soil and proposed a reinforcement mechanism through large-scale triaxial tests and pull-out tests. Existing literature on the interface characteristics between bamboo grids and soil [16] shows that the direct shear test has the advantages of simple operation and simple test preparation, and it is often used to analyze the characteristics of the interface between grids and soil. Chen et al. [17] analyzed the characteristics of the interface between a Sinocalamus affinis geogrid and weathered mudrock slag through a large-scale direct shear test and pull-out test and proposed the weaving technology of the Sinocalamus affinis geogrid and the construction technology of a reinforced embankment. Zhang et al. [18] discussed the interface friction characteristics of grass ashimproved soil reinforced by bamboo through an indoor large-scale direct shear test and proved the application of bamboo reinforcement for a road in preliminary engineering for drilling. The collapse of soil is also worthy of attention. Fattah et al. [19-24] done a lot of work on gypseous soil and adopted various methods to deal with collapsible gypseous soils.

Durability is the premise of the application of bamboo tendon grating. Although the natural durability months of Phyllostachys pubescens can reach 24 months, the necessary anticorrosion treatment should be carried out in engineering application. Wang [25] used water solvent preservatives ACQ and $\mathrm{CuAz}$ to treat bamboo. The effects of agent concentration on bending strength and bending elastic modulus were compared and analyzed. Lv [26] applied the bamboo tendon grating to the high-fill soil slope and used "asphalt boiling" for anticorrosion treatment. After more than ten years, the excavated bamboo tendon grating was not corroded. Yang [27] used the tar impregnation method to carry out anticorrosion treatment on bamboo tendon grating and found that the anticorrosion treatment had no obvious effect on the mechanical properties of bamboo tendon grating.

To sum up, bamboo tendon grating is a good reinforced flexural tensile material for subgrade soil, which has received much attention. There have been many studies on the mechanical properties of bamboo-reinforced soil and its interaction with soil, but there are few studies on its interface 
characteristics, especially the influencing factors and laws of loess interface. However, the interface characteristics of bamboo-reinforced soil directly affect the safety and stability of subgrade. On this basis, this paper studied on the characteristics of the interface between bamboo grids and reinforced soil of high-filled embankments in loess areas. A large-scale monotonic direct shear test was carried out. The influential factors such as vertical stress, shear rate, grid spacing, and packing compactness on the development law of shear stress and shear strength were analyzed, and the related mechanism was discussed.

\section{Large-Scale Direct Shear Test}

Large-scale direct shear tests with different vertical stresses, shear rates, grid spacings, and fill densities were conducted according to the interface characteristics of loess reinforced with bamboo grids.

2.1. Test Materials. In the experiment, 5-6-year-old moso bamboo in a loess area with a chest-height diameter of more than $50 \mathrm{~mm}$ and wall thickness of $2-3 \mathrm{~mm}$ was selected. Bamboo strips with a width of $20 \mathrm{~mm}$ were used. At the vertical and horizontal intersections, wire \# 8 with a diameter of $4 \mathrm{~mm}$ was used to fix the strips and form bamboo grids. As the test time was short, asphalt paint was used as anticorrosion and waterproof treatment before the test, as shown in Figure 5.

Refer to the ASTM standard "Bamboo-Determination of Physical and Mechanical Properties" (ISO 22157-1) and "Testing Methods for Physical and Mechanical Properties of Bamboo Used in Building" (JG/T 199-2007) for the test of mechanical properties of bamboo grids. The mechanical test is shown in Figure 6, and the results are presented in Table 1.

To study the influence of the weaving technology on the interface characteristics of bamboo grids, $1 / 2,1 / 4$, and $1 / 8$ spacings of the transverse and longitudinal ribs were tested. Bamboo grids with internal grid sizes of $270 \mathrm{~mm} \times 200 \mathrm{~mm}$, $125 \mathrm{~mm} \times 125 \mathrm{~mm}$, and $70 \mathrm{~mm} \times 55 \mathrm{~mm}$ were defined as A1, $\mathrm{A} 2$, and A3 types, respectively. The specific parameters are listed in Table 2, and the arrangement is shown in Figure 7.

A bidirectional plastic geogrid (TGSG2020) made of polypropylene was tested. The mesh size was $50 \mathrm{~mm} \times 50 \mathrm{~mm}$, as shown in Figure 8. The basic performance indices are listed in Table 3. Comparing Tables 1 and 3, it can be observed that bamboo grids with bending resistance can be used for reinforcement at the junction of new and old soils, and their mechanical properties are generally higher than those of geogrids. For example, the tensile strength of bamboo grids is nine times that of geogrids, and they also have better shear and compressive strengths, thus meeting the requirements of the "geosynthetics-plastic geogrids" code. It is feasible to apply them to the reinforcement of high-filled embankments in loess areas.

The test soil was obtained from the $\mathrm{K} 99+900$ to K100 + 300 subgrade soil in the Shanzhou section of Sanmenxia city, Henan Province, National Highway 310 project in China. Color was brown yellow, and it was completely

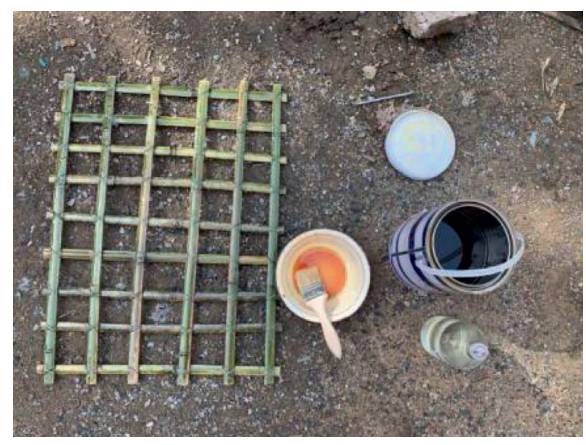

Figure 5: Bamboo grids.

renewed Quaternary loess. The test soil is fine-grained soil, its grain size distribution is shown in Table 4 , and the basic mechanical properties are shown in Table 5.

2.2. Test Plan. A large-scale direct shear apparatus designed by Zhengzhou University was used in the test, as shown in Figure 9. The size of the upper shear box was $500 \mathrm{~mm} \times 500 \mathrm{~mm} \times 150 \mathrm{~mm}$, and the size of the lower shear box was $650 \mathrm{~mm} \times 500 \mathrm{~mm} \times 150 \mathrm{~mm}$.

The test was divided into four parts. For comparison, direct shear tests of geogrid-reinforced soil and plain soil are included.

2.2.1. Test for the Influence of Reinforcement Type on the Interface Characteristics. The shear characteristics of the interface between bamboo grid-reinforced soil, geogridreinforced soil, and plain soil under different vertical stresses were compared. The shear rate was $1 \mathrm{~mm} / \mathrm{min}$, the relative compaction was 0.90 , and the vertical stresses were 100, 200, 300 , and $400 \mathrm{kPa}$, as listed in Table 6 .

\subsubsection{Test for the Influence of Shear Rate on the Interface} Characteristics. The shear characteristics of the interface between bamboo grids and reinforced soil under different shear rates were compared. The vertical stress was $200 \mathrm{kPa}$, the relative compaction was 0.90 , and the shear rates were 1 , 3,5 , and $7 \mathrm{~mm} / \mathrm{min}$, as listed in Table 7 .

\subsubsection{Test for the Influence of Bamboo Grid Spacing on the} Interface Characteristics. The shear characteristics of the interface between bamboo grids and reinforced soil under different spacings were compared. The shear rate was $1 \mathrm{~mm} /$ $\mathrm{min}$, the relative compaction was 0.90 , and the grid spacing sizes were $270 \mathrm{~mm} \times 200 \mathrm{~mm}, 125 \mathrm{~mm} \times 125 \mathrm{~mm}$, and $70 \mathrm{~mm} \times 55 \mathrm{~mm}$. This scheme is presented in Table 8 .

\subsubsection{Test for the Influence of Compactness on the Interface} Characteristics. The shear characteristics of the interface between bamboo grids and reinforced soil under different degrees of compactness were compared. The shear rate was $1 \mathrm{~mm} / \mathrm{min}$, and the compaction coefficients were $0.90,0.85$, and 0.80 , as listed in Table 9 . 


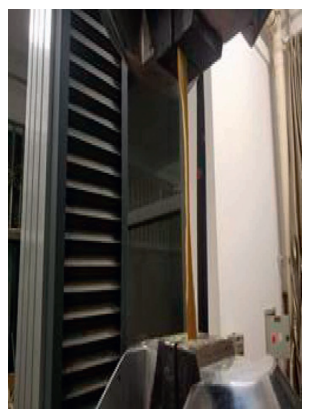

(a)

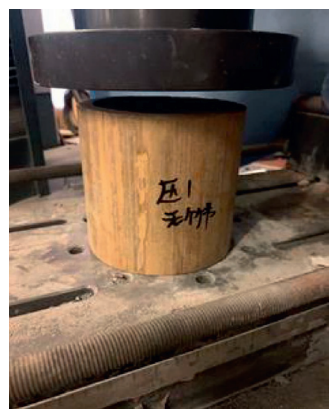

(b)

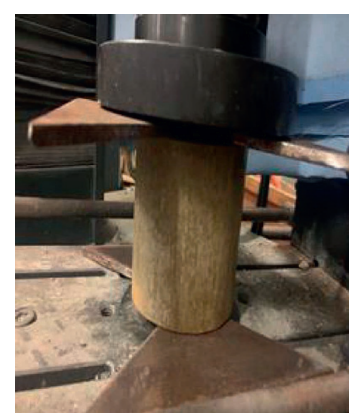

(c)

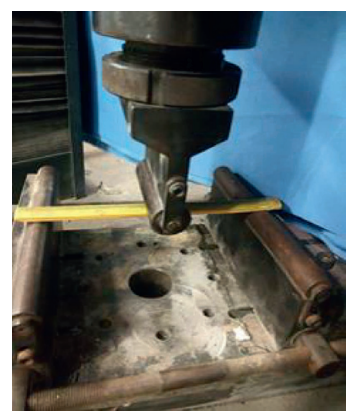

(d)

FIguRE 6: Test of mechanical properties of bamboo. (a) Tension-parallel. (b) Compression-parallel. (c) Shear-parallel. (d) Bending.

TABLE 1: Basic performance indicators of bamboo.

\begin{tabular}{lcccc}
\hline $\begin{array}{l}\text { Reinforcement } \\
\text { material }\end{array}$ & $\begin{array}{c}\text { Tension } \\
\text { strength-parallel }(\mathrm{MPa})\end{array}$ & $\begin{array}{c}\text { Compression } \\
\text { strength-parallel }(\mathrm{MPa})\end{array}$ & $\begin{array}{c}\text { Shear } \\
\text { strength-parallel }(\mathrm{MPa})\end{array}$ & $\begin{array}{c}\text { Bending } \\
\text { strength }(\mathrm{MPa})\end{array}$ \\
\hline Bamboo grids & 191.714 & 74.58 & 12.05 & 120.82 \\
\hline
\end{tabular}

TABLE 2: Different arrangements of bamboo tendon grating.

\begin{tabular}{|c|c|c|c|c|}
\hline Types of bamboo tendon grating & Number of transverse ribs & Number of longitudinal ribs & Spacing size $(\mathrm{mm})$ & Mesh size \\
\hline A1 type & 3 & 3 & $270 \times 200$ & 4 \\
\hline A2 type & 5 & 4 & $125 \times 125$ & 12 \\
\hline A3 type & 9 & 6 & $70 \times 55$ & 40 \\
\hline
\end{tabular}

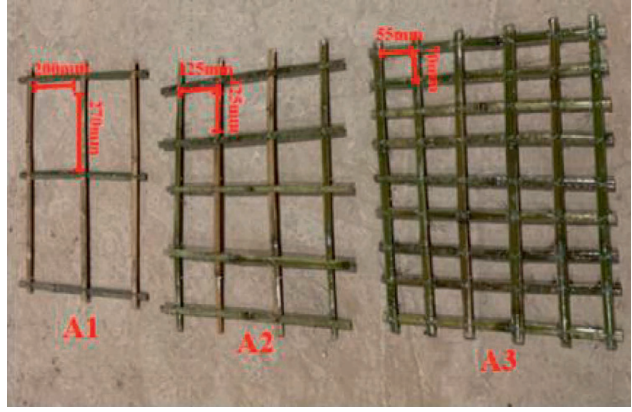

FIGURE 7: Bamboo tendon grating with different spacings.

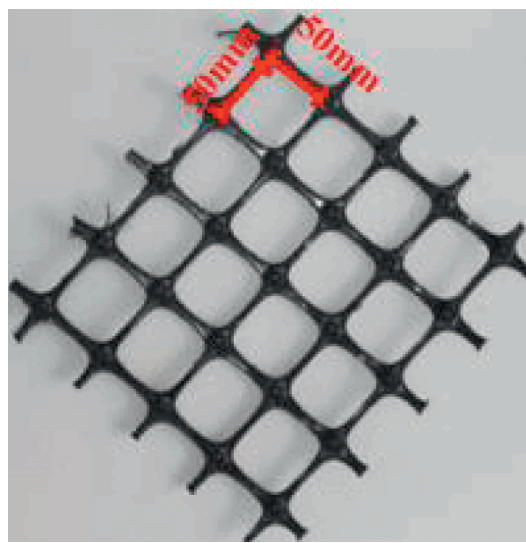

Figure 8: Biaxial geogrid.
2.3. Test Process. Refer to the standard for the soil test method (GB/T 501232019). The process was as follows: the soil was air-dried, sieved with a $2 \mathrm{~mm}$ aperture sieve, mixed with the best moisture content, and sealed until water was evenly spread. The test soil was proportioned under compactness and placed into the upper and lower shear boxes. To compact it fully, five layers (each layer of $30 \mathrm{~mm}$ ) were laid in the upper and lower shear boxes. The reinforced materials were placed at the junction of the upper and lower shear boxes. The layouts of the test materials are shown in Figure 10.

\section{Results and Analysis}

3.1. Influence of Reinforcement Type on Interface Characteristics of Reinforced Soil. The shear stress-displacement curves of the interface of the bamboo grid, geogrid, and plain soil under vertical stresses of $100,200,300$, and $400 \mathrm{kPa}$ are shown in Figure 11. As depicted in the figure, the soil shear process is divided into a linear increasing stage and a nonlinear stable convergence stage. When the shear displacement is small, it increases linearly. With a further increase in shear displacement, both reinforced soil and plain soil enter the plastic stage and realize the transformation from the strain hardening stage to the plastic strain stage.

The reinforced soil particles in the shear process are shown in Figure 12. During the shear process, with the increase in shear displacement, the soil particles in the 
TABLE 3: Basic performance indicators of the biaxial geogrid.

\begin{tabular}{|c|c|c|c|c|c|c|c|}
\hline \multirow[t]{2}{*}{ Geosynthetic } & \multirow[t]{2}{*}{ Mesh size $(\mathrm{mm})$} & \multicolumn{2}{|c|}{$\begin{array}{l}\text { Longitudinal and transverse } \\
\text { ribs' size }(\mathrm{mm})\end{array}$} & \multicolumn{2}{|c|}{$\begin{array}{l}\text { Ultimate tensile strength } \\
(\mathrm{MPa})\end{array}$} & \multicolumn{2}{|c|}{ Ultimate elongation (\%) } \\
\hline & & Transverse & Longitudinal & Transverse & Longitudinal & Transverse & Longitudinal \\
\hline Plastic geogrid & $50 \times 50$ & 50 & 50 & 20 & 20 & 13 & 15 \\
\hline
\end{tabular}

TABLE 4: The grain size distribution of the test soil.

\begin{tabular}{|c|c|c|c|c|c|c|}
\hline \multicolumn{7}{|c|}{ Particle content in different particle size range (\%) } \\
\hline \multicolumn{6}{|c|}{ Coarse-grained group } & \multirow{2}{*}{ Fine-grained group } \\
\hline & Gravel & & & Sand & & \\
\hline$>10(\mathrm{~mm})$ & $10 \sim 5(\mathrm{~mm})$ & $5 \sim 2(\mathrm{~mm})$ & $2 \sim 0.5(\mathrm{~mm})$ & $0.5 \sim 0.25(\mathrm{~mm})$ & $0.25 \sim 0.075(\mathrm{~mm})$ & $<0.075(\mathrm{~mm})$ \\
\hline 0 & 0 & 0 & 0.5 & 5.0 & 19.2 & 75.1 \\
\hline
\end{tabular}

TABLE 5: Basic performance indicators of the test soil.

Filling material Density $\left(\mathrm{g} \cdot \mathrm{cm}^{-3}\right) \quad \begin{gathered}\text { Optimum } \\ \text { moisture (\%) }\end{gathered}$ Maximum dry density $\left(\mathrm{g} \cdot \mathrm{cm}^{-3}\right)$ Liquid limit (\%) Plastic limit (\%) Plasticity index

\begin{tabular}{lllllll}
\hline Loess & 1.62 & 11.94 & 1.945 & 25 & 17 & 8.09 \\
\hline
\end{tabular}

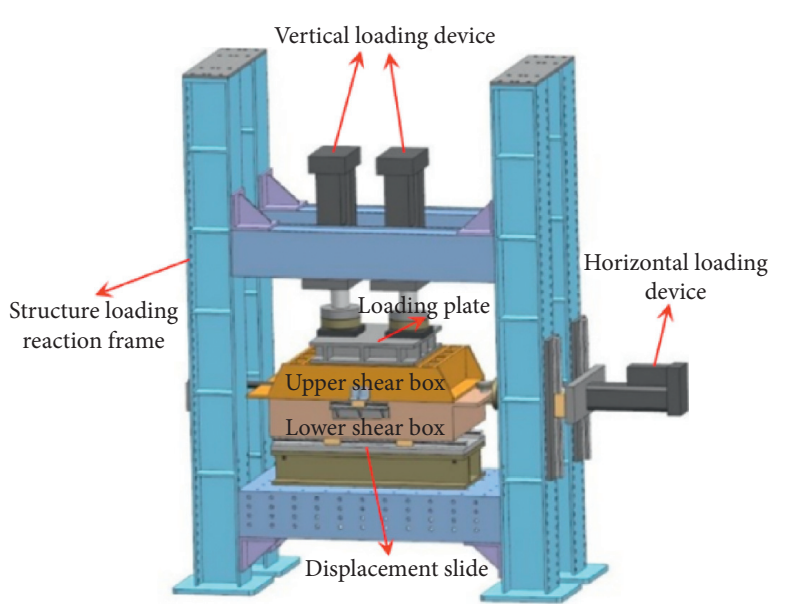

(a)

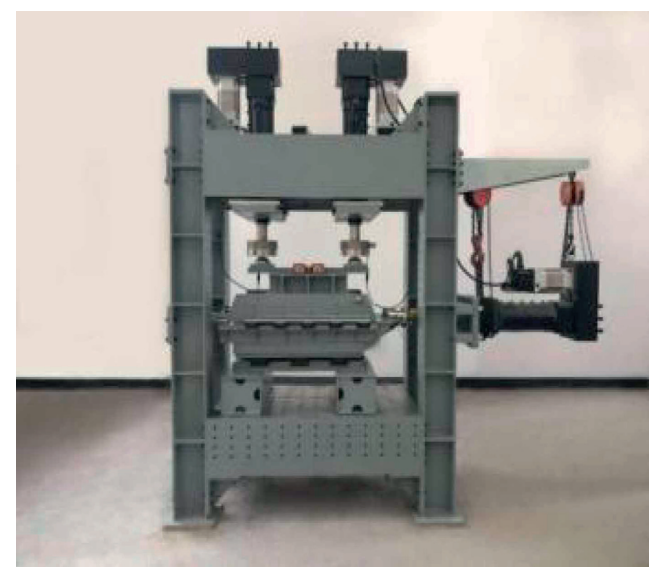

(b)

FIGURE 9: Large-scale direct shear apparatus.

TABle 6: Test schemes for different types of reinforcement.

\begin{tabular}{lcccc}
\hline Test number & Type of reinforcement & Compactness & Shear rate $(\mathrm{mm} / \mathrm{min})$ & Vertical stress $(\mathrm{kPa})$ \\
\hline A01 & Plain soil & 0.90 & 1 & $100,200,300,400$ \\
A02 & Geogrids & 0.90 & 1 & $100,200,300,400$ \\
A03 & A2-type bamboo tendon grating & 0.90 & 1 & $100,200,300,400$ \\
\hline
\end{tabular}

TABle 7: Test schemes for different shear rates.

\begin{tabular}{llccc}
\hline Test number & Types of reinforcement & Compactness & Shear rate $(\mathrm{mm} / \mathrm{min})$ & Vertical stress $(\mathrm{kPa})$ \\
\hline B01 & A2-type bamboo tendon grating & 0.90 & 1 & 200 \\
B02 & A2-type bamboo tendon grating & 0.90 & 3 & 200 \\
B03 & A2-type bamboo tendon grating & 0.90 & 5 & 200 \\
B04 & A2-type bamboo tendon grating & 0.90 & 7 & 200 \\
\hline
\end{tabular}


TABLE 8: Test schemes for bamboo tendon grating with different spacings.

\begin{tabular}{llccc}
\hline Test number & Types of reinforcement & Compactness & Shear rate $(\mathrm{mm} / \mathrm{min})$ & Vertical stress $(\mathrm{kPa})$ \\
\hline C01 & A1-type bamboo tendon grating & 0.90 & 1 & $100,200,300,400$ \\
C02 & A2-type bamboo tendon grating & 0.90 & 1 & $100,200,300,400$ \\
C03 & A3-type bamboo tendon grating & 0.90 & 1 & $100,200,300,400$ \\
\hline
\end{tabular}

TABle 9: Test schemes for different degrees of compactness.

\begin{tabular}{|c|c|c|c|c|}
\hline Test number & Types of reinforcement & Compactness & Shear rate $(\mathrm{mm} / \mathrm{min})$ & Vertical stress $(\mathrm{kPa})$ \\
\hline D01 & A2-type bamboo tendon grating & 0.90 & 1 & $100,200,300,400$ \\
\hline D02 & A2-type bamboo tendon grating & 0.85 & 1 & $100,200,300,400$ \\
\hline D03 & A2-type bamboo tendon grating & 0.80 & 1 & $100,200,300,400$ \\
\hline
\end{tabular}

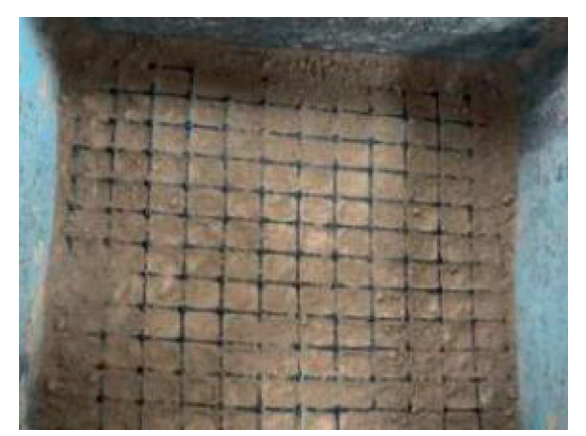

(a)

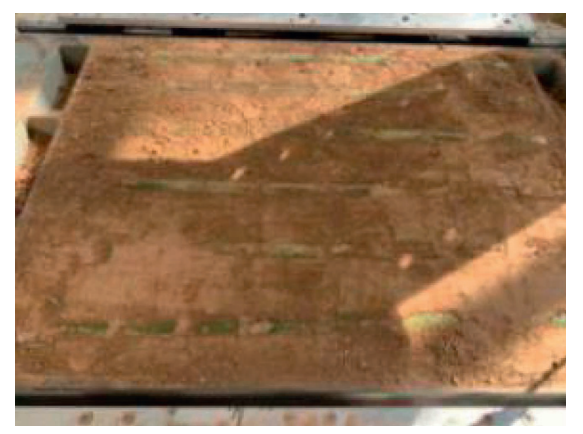

(b)

FIgURE 10: Laying of the material in the lower shear box. (a) Laying the geogrid. (b) Laying the bamboo tendon grating.

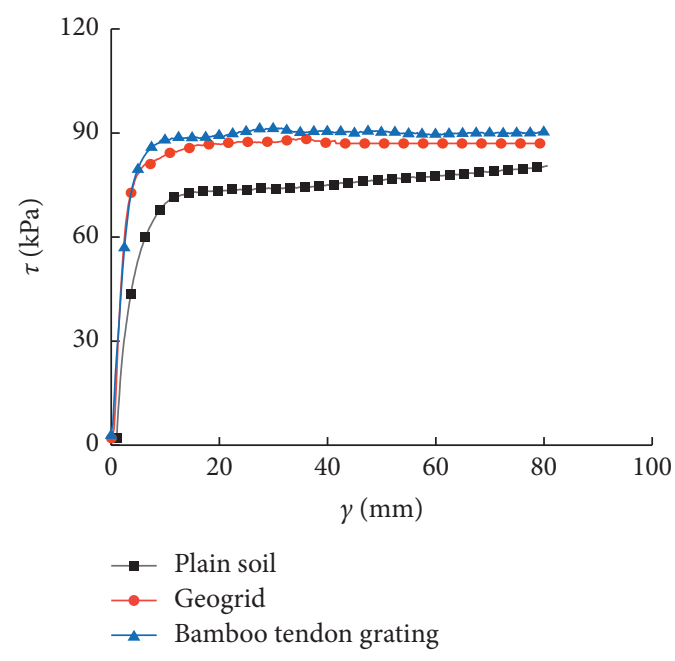

(a)

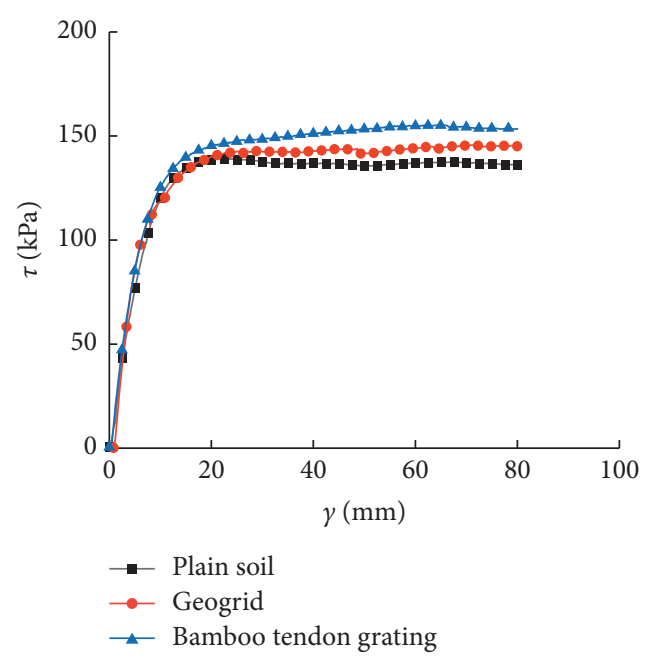

(b)

FIgUre 11: Continued. 


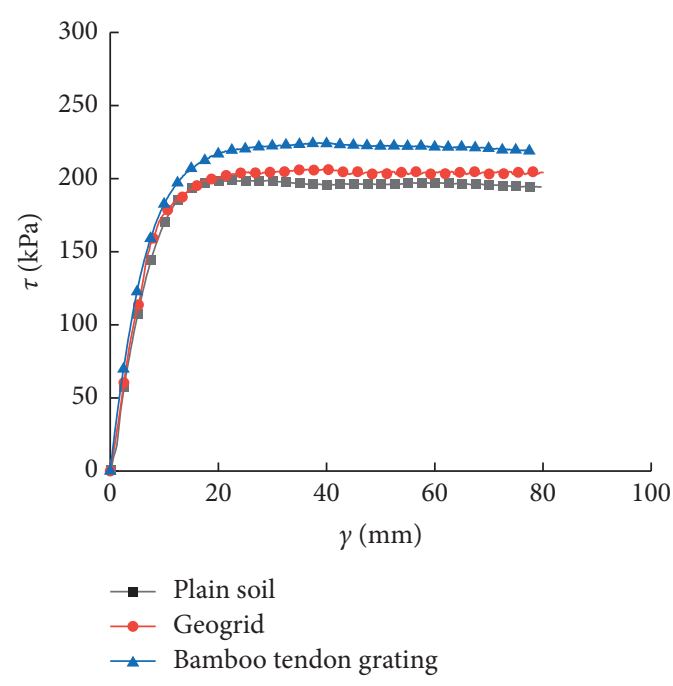

(c)

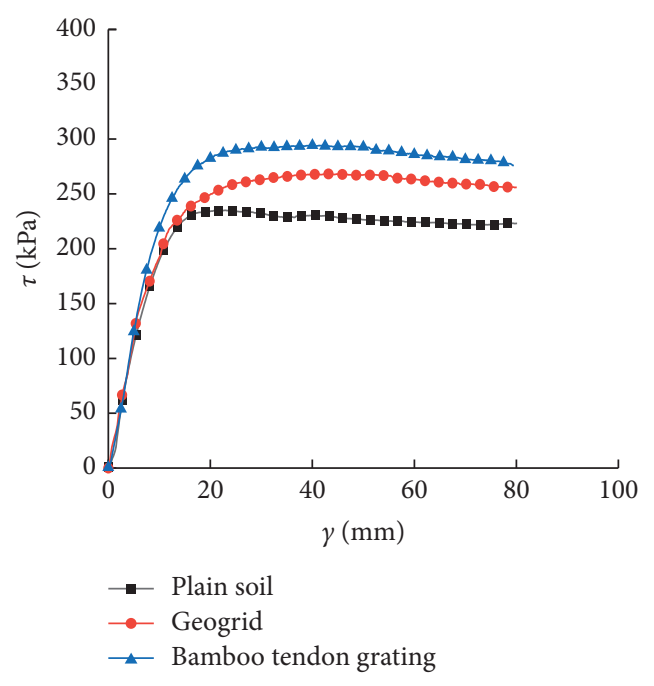

(d)

Figure 11: Shear stress-displacement curves of the reinforcement material interface under different normal stress levels: (a) $100 \mathrm{kPa}$ normal stress, (b) $200 \mathrm{kPa}$ normal stress, (c) $300 \mathrm{kPa}$ normal stress, and (d) $400 \mathrm{kPa}$ normal stress.

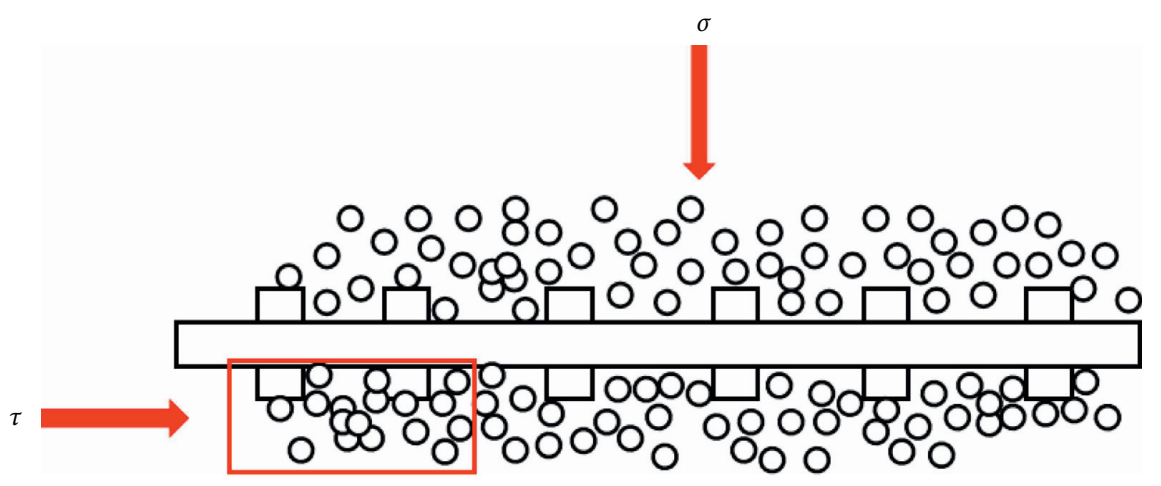

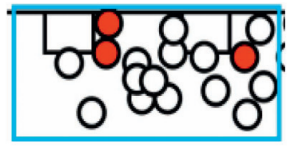

(a)

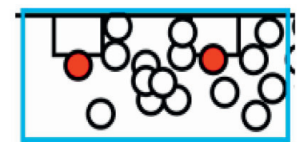

(b)

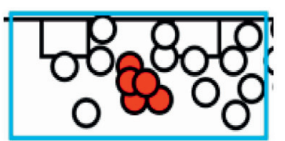

(c)

FIgURe 12: Stress diagram of soil particles in the shear process. (a) Passive friction resistance. (b) Bite force. (c) Friction shear force.

grating groove, and the upper soil particles bite each other to form a particle skeleton by continuously moving and rotating. The particle skeleton is mainly affected by the passive friction resistance (see Figure 12(a)) between the longitudinal and transverse ribs and the soil particles during the movement, the bite force between the particle skeletons (see Figure 12)(b), and the friction shear force on the grid surface (see Figure 12(c)).

Figure 13 shows the surface of the reinforcement materials with different roughness values. Under the same vertical stress condition, the curve peak value of bambooreinforced soil was the largest, followed by that of geogridreinforced soil and plain soil (see Figure 11). This occurs because the surface of the bamboo grid is rougher than that of the geogrid in the shear process (see Figure 13), which produces a greater friction shear force on the loess particles. At the same time, bamboo grids have good mechanical properties and can effectively embed into the soil, and the sides of the grids have a large passive friction resistance force on the loess particles. Thus, the shear stress peak value of the soil reinforced with bamboo bars is the largest.

The shear strength fitting curves of the soil reinforced with bamboo grids and geogrids and the plain soil in the test are shown in Figure 14. The results of the interface friction tests are presented in Table 10. 


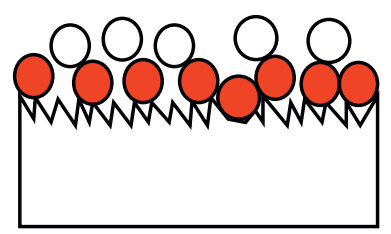

(a)

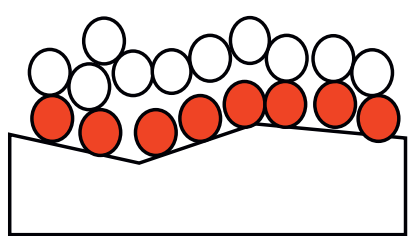

(b)

FIgURE 13: Stress diagram of soil particles on the surface of reinforced materials with different roughness. (a) Soil particles and bamboo reinforcement surface. (b) Soil particles and biaxial geogrid surface.

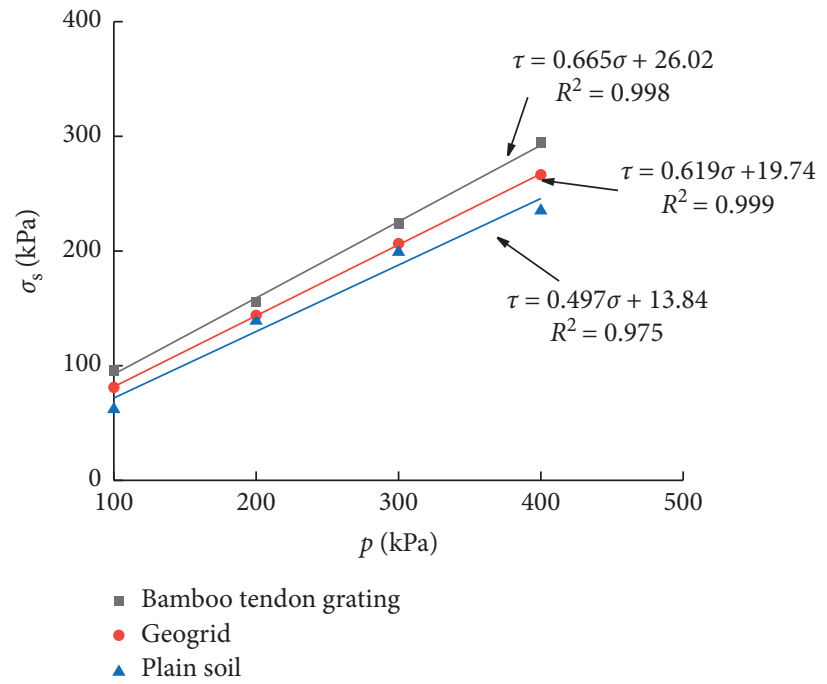

FIGURE 14: Relationship between shear strength and normal stress levels of different reinforced materials.

TABLE 10: Test results of interface friction between reinforcement and soil.

\begin{tabular}{|c|c|c|c|c|}
\hline Types of reinforcement & $p(\mathrm{kPa})$ & $\sigma_{s}(\mathrm{kPa})$ & $\varphi /^{\circ}$ & $c(\mathrm{kPa})$ \\
\hline \multirow{4}{*}{ Reinforced soil with bamboo tendon grating } & 100 & 95.61 & \multirow{4}{*}{33.64} & \multirow{4}{*}{26.02} \\
\hline & 200 & 155.16 & & \\
\hline & 300 & 224.44 & & \\
\hline & 400 & 294.32 & & \\
\hline \multirow{4}{*}{ Reinforced soil with the geogrid } & 100 & 81.04 & \multirow{4}{*}{31.71} & \multirow{4}{*}{19.74} \\
\hline & 200 & 143.88 & & \\
\hline & 300 & 206.48 & & \\
\hline & 400 & 266.48 & & \\
\hline Plain soil & 100 & 61.88 & 26.42 & 13.84 \\
\hline
\end{tabular}

It can be observed from Table 10 that the shear strength index of the reinforced soil is significantly increased. The cohesion of bamboo-reinforced soil is $21.47 \%$ higher than that of geogrid-reinforced soil and $46.81 \%$ higher than that of plain soil. The internal friction angle is $5.74 \%$ higher than that of geogrid-reinforced soil, which is $24.13 \%$ higher than that of plain soil.

The reasons are as follows: (1) the surface roughness of bamboo grids is larger than that of geogrids, and the friction shear force is larger when shear displacement occurs. The embedding and occluding effect of bamboo ribs on soil particles improves the passive friction resistance. (2) The tensile strength of bamboo grids is higher than that of the geogrid, and their elongation is lower than that of the geogrid, which results in better lateral restraint and stability. Bamboo grids can improve soil strength. Therefore, the bamboo grid-reinforced soil can effectively improve the shear performance of the soil.

3.2. Influence of Shear Rate on Interface Characteristics of Reinforced Soil. Figure 15 shows the shear stress-shear displacement curve of the interface under different shear rates and different reinforcement types under vertical stresses of $200 \mathrm{kPa}$. It can be observed from Figure 15 that, under different shear rates, the shear stress of different soils with shear displacement has the same variation law. The shear process of soil is divided into linear increasing and 


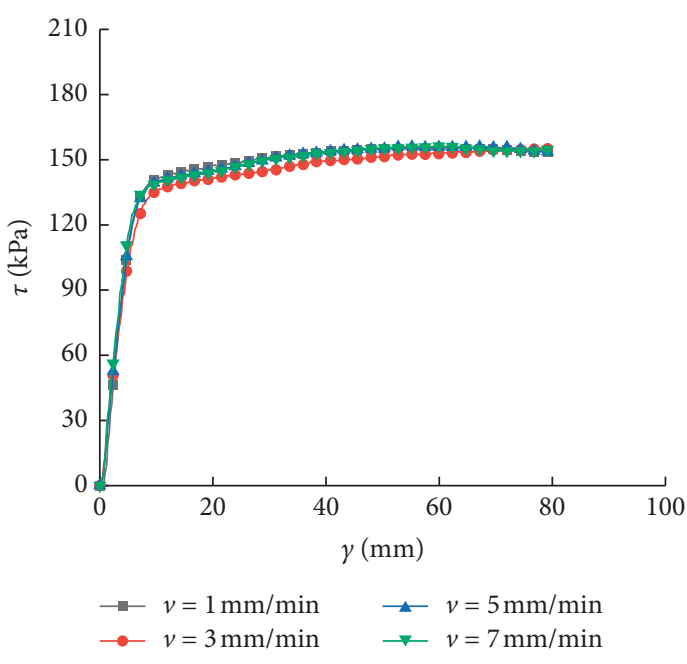

(a)

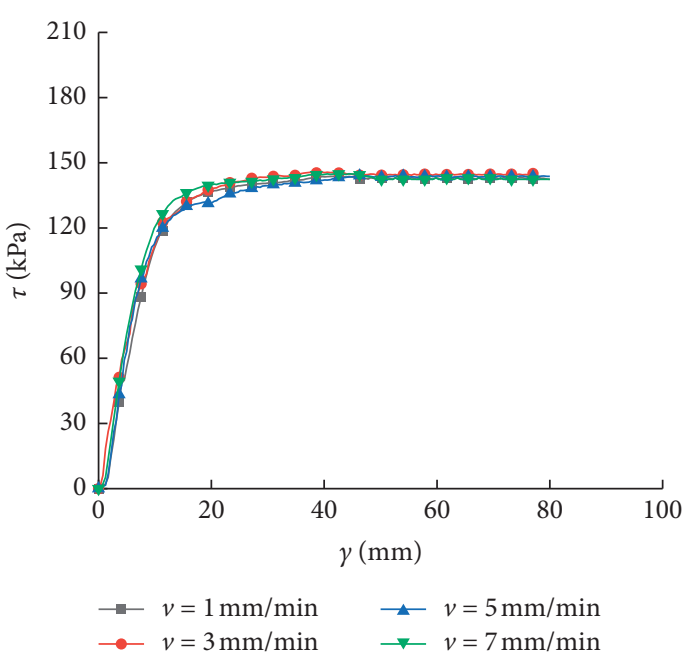

(b)

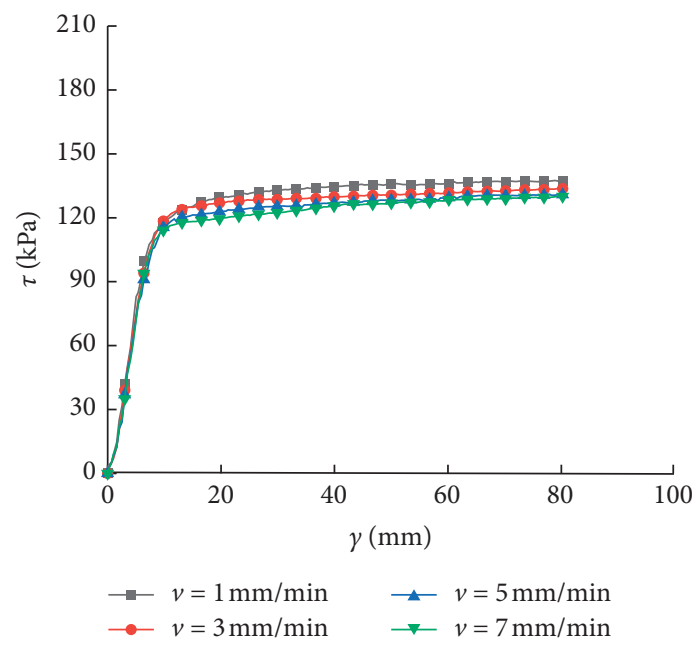

(c)

FIGURE 15: Shear stress-displacement curves of reinforced materials under different shear rates. (a) Reinforced soil with bamboo tendon grating. (b) Reinforced soil with the geogrid. (c) Plain soil.

nonlinear stable convergence. When the shear displacement is small, it increases linearly. With the increase of shear displacement, it enters the plastic stage and realizes the transition from the strain hardening stage to the plastic strain softening stage.

The curves of shear strength versus shear rate of soils with different grid types are shown in Figure 16. From the analysis of Figure 16, it can be found that the shear rate has little effect on the shear strength of bamboo-reinforced soil and geogridreinforced soil, which is consistent with the law obtained in. Especially for bamboo-reinforced soil, the effect is small. For example, the shear strength change rate of bamboo-reinforced soil is only $0.46 \%$, which is less than $1.42 \%$ of geogridreinforced soil. This is because bamboo has good deformation performance and increases the stability of soil and shear resistance. The curves of plain soil decrease with increasing shear rate. This is because the shear rate affects the dissipation of pore water pressure, and a lower shear rate is beneficial for the dissipation of pore water pressure.
3.3. Influence of Bamboo Grid Spacing on Interface Characteristics of Reinforced Soil. The bamboo grid has a threedimensional structure. Its surface has holes and is rough. Therefore, its interaction with the soil is more complex. These interaction factors are closely related to the grid spacing because the spacing affects the friction, shear strength, passive friction resistance, and other factors. Research on spacing not only aims at meeting the requirements of bearing capacity but also at optimizing the cost. Interface shear strength tests of the A1, A2, and A3 types of bamboo grids were carried out to analyze the shear strength variation at different spacings.

Figure 17 shows the curves of shear stress-shear displacement with different spacings. From Figure 17, it can be found that the peak shear stress of type A1 is less than that of types A2 and A3. The analysis shows that the spacing of type $\mathrm{A} 1$ is larger, and the embedding effect of sparse transverse ribs and longitudinal ribs on soil is lower than that of types $\mathrm{A} 2$ and $\mathrm{A} 3$. The contact surface on the soil of type A1 is less 


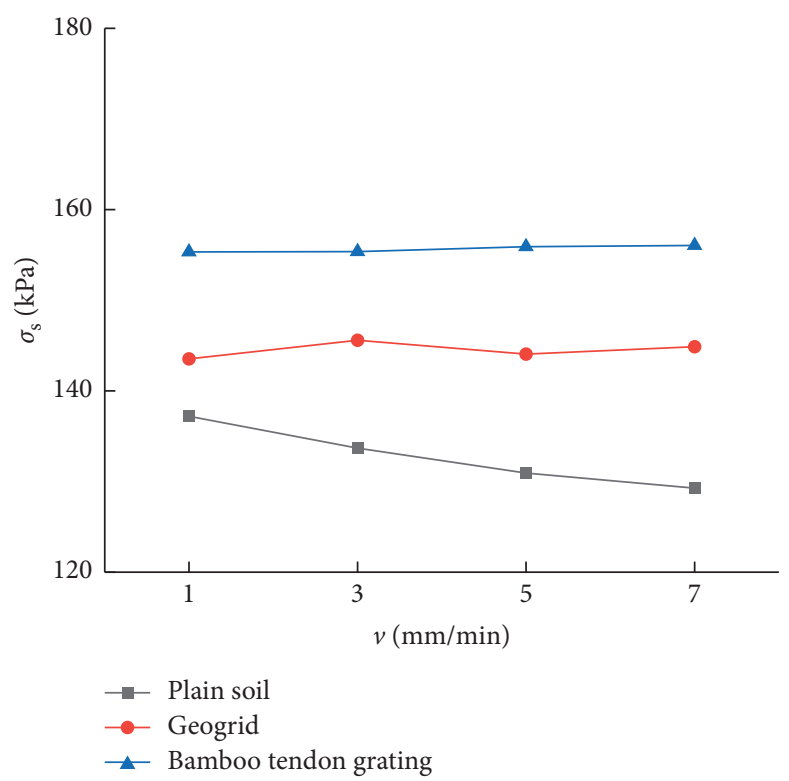

FIGURE 16: Shear strength of the soil interface under different shear rates for different reinforced materials.

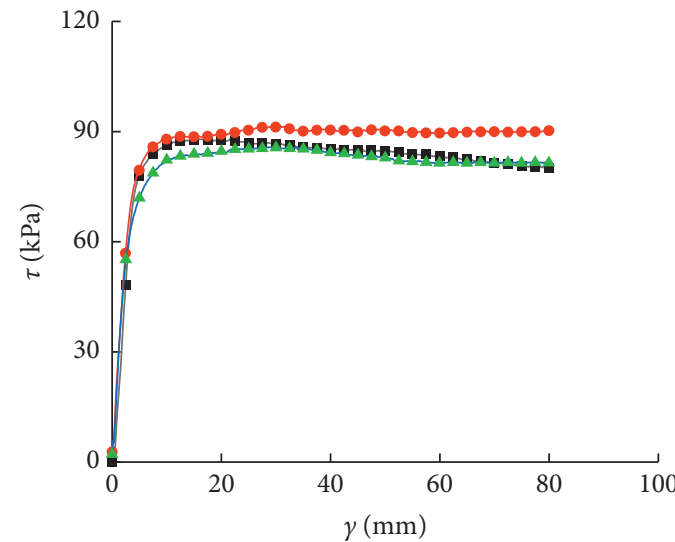

- A1-type bamboo tendon grating

$\rightarrow$ A2-type bamboo tendon grating

$\rightarrow$ A3-type bamboo tendon grating

(a)

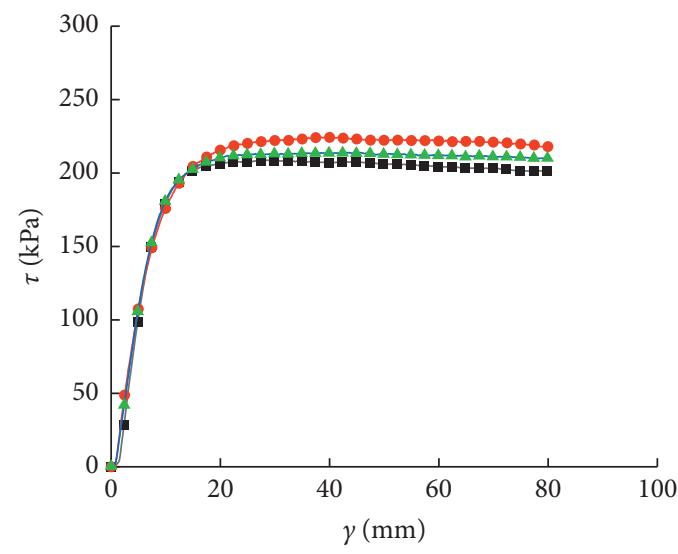

- A1-type bamboo tendon grating

$\rightarrow$ A2-type bamboo tendon grating

$\rightarrow$ A3-type bamboo tendon grating

(c)

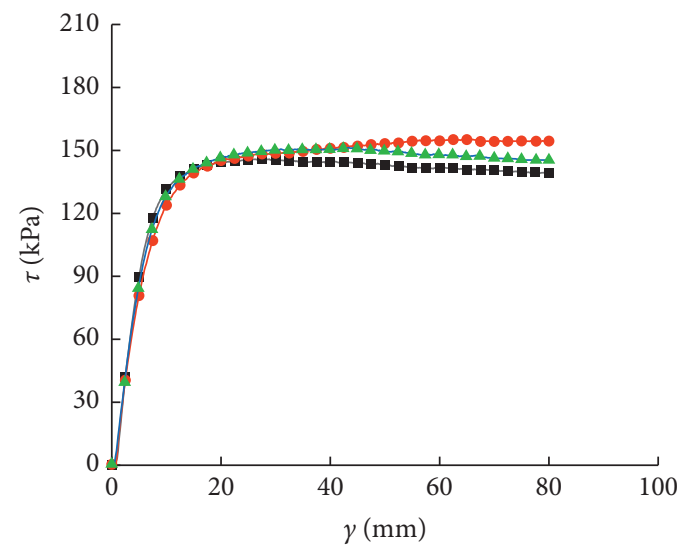

- A1-type bamboo tendon grating

- A2-type bamboo tendon grating

$\rightarrow$ A3-type bamboo tendon grating

(b)

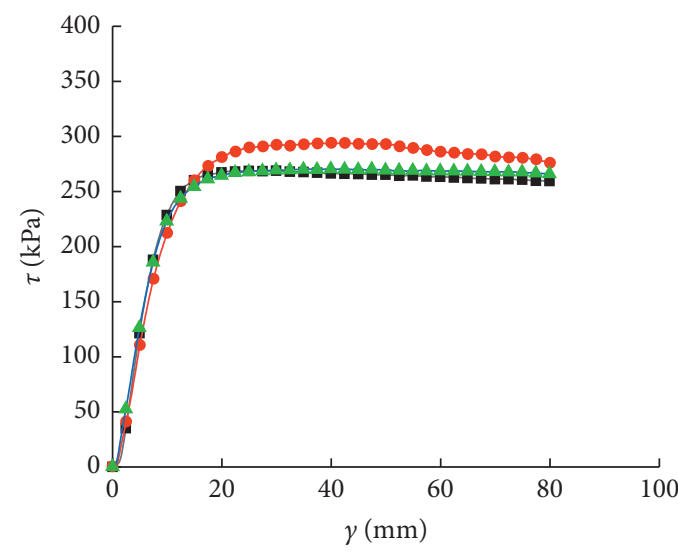

- A1-type bamboo tendon grating

$\rightarrow$ A2-type bamboo tendon grating

$\rightarrow$ A3-type bamboo tendon grating

(d)

Figure 17: Shear stress-displacement curves of reinforced bamboo tendon grating with different spacings: (a) $100 \mathrm{kPa}$ normal stress, (b) $200 \mathrm{kPa}$ normal stress, (c) $300 \mathrm{kPa}$ normal stress, and (d) $400 \mathrm{kPa}$ normal stress. 


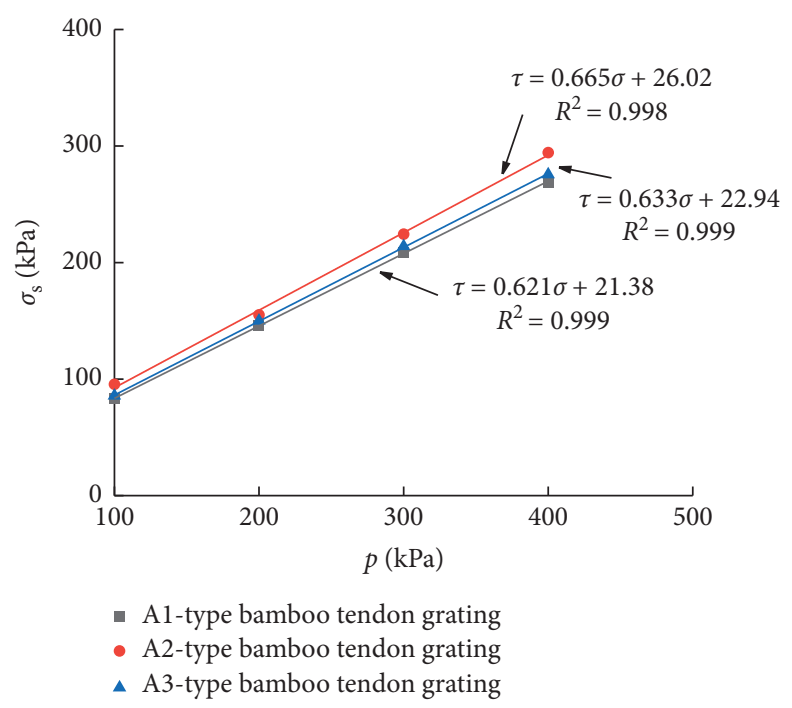

FIGURE 18: Relationship between shear strength and normal stress levels of reinforced bamboo tendon grating with different spacings.

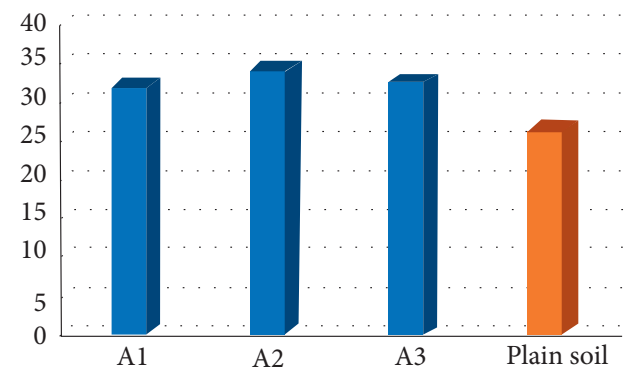

(a)

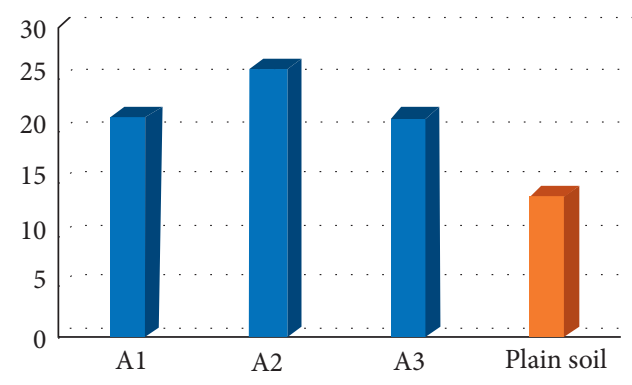

(b)

Figure 19: Variation in shear strength of different reinforced soils. (a) Internal friction angle. (b) Cohesion.

than that of types A2 and A3, resulting in less friction shear strength and passive friction resistance.

The peak shear stress of the A3 type is less than that of the A2 type because the effective embedded area of the soil will be reduced owing to the close spacing, and the contact surface of the soil will be reduced owing to the small opening of the grid. Thus, the shear strength of the soil will be reduced. Although a dense spacing increases the friction shear stress on the grid surface and the passive friction resistance on the side of the grid, the overall shear performance of the reinforced soil decreases.

The shear strength curves of the A1, A2, and A3 types of bamboo grids are fitted, as shown in Figure 18. The results of the fitting are presented in Figure 19. As depicted in Figure 19, compared with plain soil, the internal friction angle and cohesion of the A1, A2, and A3 bamboo bar grids are improved, with an average increase of $23.39 \%$ and $40.57 \%$, respectively. However, the rate of increase is not the same. The A2 type had the largest increase, where the internal friction angle increased by $19.25 \%$, and the cohesion increased by $47.26 \%$. In this test, the A 2 type is the best spacing for bamboo grids. In practical engineering applications, the loose and dense spacing of bamboo grids will affect the strength of reinforced soil, and thus, it is necessary to determine the optimal spacing according to the test.

3.4. Influence of Compactness on Interface Characteristics of Reinforced Soil. The shear strength straight line of bambooreinforced soil with different degrees of compactness was fitted, as shown in Figure 20. It can be observed from Figure 20 that the greater the relative compaction, the greater the shear strength index. For example, when relative compaction decreases from 0.9 to 0.85 and 0.8 , the cohesion decreases from 26.02 to 25.92 and $25.24 \mathrm{kPa}$, respectively, whereas the internal friction angle decreases from $33.62^{\circ}$ to $30.87^{\circ}$ and $28.41^{\circ}$, respectively.

This is because the crushing and reconstitution of particles require extra work from external forces, which increases the internal friction angle on the shear plane. The change in compactness changes the spacing of soil particles and pore size, thus changing the mechanical properties of the soil. In direct shear, the work of compact packing is greater than that of loose packing in the process of crushing and rearrangement, and the index of internal friction angle is significantly improved. In addition, the higher the relative 


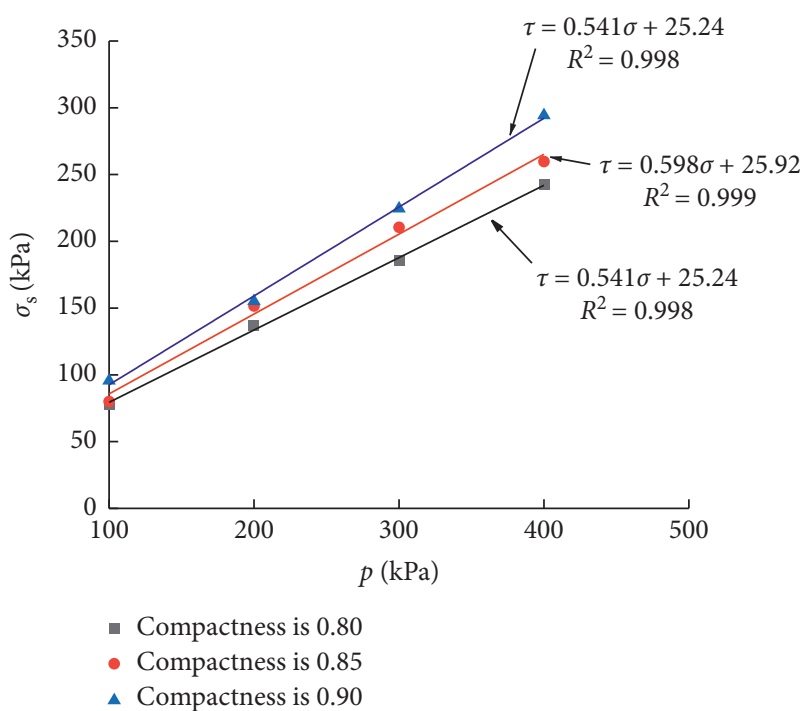

FIgURE 20: Relationship between shear strength and normal stress levels of reinforced bamboo tendon grating soils with varying compactness.

compaction is, the closer the soil and grid are, and the interlocking increases, resulting in an improved reinforcement effect.

\section{Conclusions}

In this study, a series of large-scale direct shear tests were carried out to study the shear characteristics of the interface between bamboo grids and loess, and the related mechanisms were discussed. The conclusions are as follows:

(1) The results show that bamboo grids have good bending resistance, making them suitable for the interface of high and steep slopes to prevent soil sliding. The mechanical properties of the bamboo grids are good, and they meet the specification requirements. The durability of bamboo grids through chemical anticorrosion treatment can also meet the need of the project. Therefore, it is feasible to apply them into the reinforcement of high-filled loess subgrades.

(2) Under different vertical stresses, the peak shear stress of bamboo-reinforced soil is higher than that of geogrid-reinforced soil and plain soil, which is caused by the passive friction resistance between the vertical and horizontal ribs and soil particles, the bite force between the particle skeletons, and the surface friction of grids. Compared with geogrids, bamboo grids can improve the shear strength of the soil.

(3) The shear rate has little effect on the shear strength of bamboo-reinforced soil and geogrid-reinforced soil, especially on bamboo-reinforced soil. Under different shear rates, the shear strength change rate of bamboo-reinforced soil is only $0.46 \%$, which is less than $1.42 \%$ of geogrid-reinforced soil due to the better deformation ability of bamboo. This increases the stability and shear resistance of the soil.
(4) When the spacing changes from sparse to dense, the soil embedment, size of the contact surface, and friction resistance on the surface and side of the grid change. The shear performance first increases and then decreases, and there is an optimal spacing. In practical engineering applications, loose and dense spacing of bamboo tendon grating will affect the strength of the reinforced soil, and it is necessary to determine the optimal spacing based on tests.

(5) The density of filling material affects the shear performance of soil reinforced with bamboo tendon grating. The higher the relative compaction, the greater the cohesion and internal friction angle, which are related to the spacing of soil particles and pores. In practical engineering applications, increasing compactness can increase the interlocking between grids and soil, so it improves the reinforcement effect.

\section{Data Availability}

The data used to support the findings of this study are available from the corresponding author upon request.

\section{Conflicts of Interest}

The authors declare that they have no conflicts of interest.

\section{Acknowledgments}

The authors wish to thank the National Natural Science Foundation of China (no. 51909243) and Key Scientific and Technological Project of Henan Province (202102310293) for the support.

\section{References}

[1] C. S. Eun, H. K. Hyoun, and J. P. Jeong, "Reinforcement efficiency of bearing capacity with geocell shape and filling materials," KSCE Journal of Civil Engineering, vol. 21, no. 5, pp. 1648-1656, 2017.

[2] S. X. Wang, Study on Differential Settlement Standard and Controlling Techology of High Embankment in Mountain Area, Master Thesis, Chang'an University, Xi'an, China, 2008.

[3] W. L. Xie, Deformation and Stability Analysis of Reinforced High Embankment in the Loess Region, D's Thesis, Northwest University, Kirkland, Washington, USA, 2004.

[4] Q. Wang, X. Wen, J. Jiang, C. Zhang, and Z. Shi, "Experimental study on performance of multidirectional geogrid and its application in engineering of high slope," Journal of Wuhan University of Technology-Materials Science Edition, vol. 29, no. 4, pp. 704-711, 2014.

[5] Y. L. Xie, Y. H. Yu, and X. H. Yang, "Application study of treating differential settlement of subgrade with geocell," China Journal of Highway and Transport, vol. 17, no. 4, pp. 7-11, 2004.

[6] G. Khosrow, "Bamboo as reinforcement in structural concrete elements," Cement and Concrete Composites, vol. 27, pp. 637-649, 2005.

[7] T. Y. Lo, H. Z. Cui, P. W. C. Tang, and H. C. Leung, "Strength analysis of bamboo by microscopic investigation of bamboo 
fibre," Construction and Building Materials, vol. 22, no. 7, pp. 1532-1535, 2008.

[8] D. F. Katleen and R. Ronald, "One laminated bamboo-frame house per hectare per year," Construction and Building $\mathrm{Ma}$ terials, vol. 23, no. 1, pp. 210-218, 2009.

[9] G. Song, X. C. Bian, J. Q. Jiang, and Y. M. Chen, "Deformation behaviors and bearing capacity of geosynthetics-reinforced pavement," Journal of Shanghai Jiaotong University, vol. 45, no. 5, pp. 653-658, 2011.

[10] H. Ismail, M. R. Edyham, and B. Wirjosentono, "Bamboo fibre filled natural rubber composites: the effects of filler loading and bonding agent," Polymer Testing, vol. 21, no. 2, pp. 139-144, 2002.

[11] Z. P. Shao, "Mechanical behavior of bamboo with large deformation: I. the relationship between stress and strain," China Wood in Dustry, vol. 17, no. 2, pp. 12-14+32, 2003.

[12] A. P. Zhou, D. S. Huang, S. S. Che, and P. D. Zhang, "Distribution of vascular bundles of bamboo and its tensile mechanical performances," Journal of Building Materials, vol. 15, no. 5 , pp. $730-734,2012$.

[13] H. T. Li, D. D. Wei, J. W. Su, C. G. Yuan, and G. Chen, "Experimental study on PSBL under eccentric compression," Journal of Building Materials, vol. 19, no. 3, pp. 561-565+583, 2016.

[14] J. G. Wei, S. H. Huang, W. Wang, J. Wang, and B. Chen, "Triaxial shear and finite element comparative test of bamboo reinforcement," Shanxi Architecture, vol. 40, no. 1, pp. 70-72, 2014.

[15] L. Wang, W. X. Fu, J. L. Gao, J. H. Deng, and S. Xu, "Use of bamboo geo-grid for reinforcement of expressway soft subgrade," Chinese Journal of Underground Space and Engineering, vol. 10, pp. 1899-1903, 2014.

[16] K. F. Liu, J. P. Xu, Q. S. Zhou, X. Y. Xie, and Y. Hu, "Largescale direct shear tests on properties of geogrid-soil interfaces," Chinese Journal of Geotechnical Engineering, vol. 41, pp. 185-188, 2019.

[17] J. Chen, W. X. Fu, F. Dai, and J. H. Deng, "Mechanical behaviors of bamboo geogrid in reinforcing filling embankment," Chinese Journal of Geotechnical Engineering, vol. 38, no. 1, pp. 174-179, 2017.

[18] W. Zhang, H. Wen, and Z. W. Zhang, "The switching power supply electromagnetic analysis general procedures and simulation," Applied Mechanics and Materials, vol. 644-650, pp. 3829-3833, 2014.

[19] M. Y. Fattah, M. M. Al-Ani, and M. T. A. Al-Lamy, "Wetting and drying collapse behaviour of collapsible gypseous soils treated by grouting," Arabian Journal of Geosciences, vol. 8, no. 4, pp. 2035-2049, 2015.

[20] I. H. Obead, H. A. Omran, and M. Y. Fattah, "Implementation of artificial neural network to predict the permeability and solubility models of gypseous soil," Pertanika Journal of Science é Technology, vol. 29, no. 1, pp. 107-122, 2021.

[21] M. Y. Fattah and B. A. Dawood, "Time-dependent collapse potential of unsaturated collapsible gypseous soils," World Journal of Engineering, vol. 17, no. 2, pp. 283-294, 2020.

[22] A. L. Hayal, A. M. B. Al-Gharrawi, and M. Y. Fattah, "Collapse problem treatment of gypseous soil by nanomaterials," International Journal of Engineering, vol. 33, no. 9, pp. 17371742, 2020.

[23] M. Y. Fattah, I. H. Obead, and H. A. Omran, "A study on leaching of collapsible gypseous soils," International Journal of Geotechnical Engineering, pp. 1-11, 2019.

[24] M. Y. Fattah, M. K. Hameedi, M. K. Hameedi, and M. F. Aswad, "Determination of collapse potential of gypseous soil from field and laboratory tests," Diyala Journal of Engineering Sciences, vol. 10, no. 2, pp. 75-85, 2017.

[25] Y. M. Wang, Study on the Decay Resistance Property and the Choice of Preservatives of Bamboo, Master Thesis, Inner Mongolia Agricultural University, Hohhot, China, 2004.

[26] T. Lv, The Research and Application of the Bamboo Tendons in the Reinforced Retaining Slope, Master Thesis, Chongqing University, Chongqing, China, 2007.

[27] S. G. Yang, "Discussion on bamboo reinforcement physical mechanical property of reinforced composite soil," Shanxi Architecture, vol. 35, no. 34, pp. 168-169, 2009. 